\title{
The Virtual Space of the Dynamic Hypermedia Device, a Habitable Space
}

\begin{abstract}
The hybrid contemporary space, which integrates urban and interactive virtual spaces, implies particular ways of inhabiting that suggests new identities, promoting the constant alternation between its different worlds. This article proposes to analyze and understand the design, construction and appropriation processes in this new social space-time. These processes are not only guaranteed by the accessibility to new media, but they involve the organization of complex strategies which included the development of instruments and landscapes that allow the migrations and interweaving between two realities: the urban and the virtual. This project generated an accumulation of unforgettable experiences that turned into a multiplicity of words and images that expanded through informal media or planned strategies. These activities allow reflecting upon the behaviors, meanings, and diverse thresholds that were constructed by the actors themselves during this process, and suggest new ways of being-in-the-world.
\end{abstract}

\section{INTRODUCTION}

The purpose of this article is to consider the characteristics of the virtual space of a Dynamic Hypermedia Device as a habitable space that promotes its appropriation. This issue is examined in the author's ongoing doctoral thesis, entitled "The Interface-Space of the Dynamic Hypermedia Device""; in projects that are part of the Research, Development, and Technology Transfer Program "Dynamic Hypermedia Device"; and in a high-impact R\&D project for public universities of the Center-East region of Argentina, at the Centro Internacional Franco Argentino de Ciencias de la Información y de Sistemas - CIFASIS $(\text { CONICET-UNR-UPCAM })^{2}$.

1 Resolution $\mathrm{N}^{\circ} 1059 / 2009$ D. Escuela de Posgrado de la Facultad de Humanidades y Artes de la Universidad Nacional de Rosario. Sponsored by PROMAC-POS Rector's Res. "C.S." No 173/10 y No209/09, and by the CAI+D’09 Research Program at Universidad Nacional del Litoral, Santa Fe.

2 For more information, see http://www.cifasis-conicet.gov.ar/index.php?grupo=5 PICTO-2010-0143 "Hacia el desarrollo y utilización de Repositorios de Acceso Abierto para Objetos Digitales Educativos en el contexto de las universidades públicas de la región centro-este de Argentina" Convocatoria PICTO CIN II, Resolución ANPCYT Nº330/2011. 
According to San Martin [1], a Dynamic Hypermedia Device-DHD- is a complex entity that results from the integration of two indissociable and interdependent dimensions: a set of technologies and social aspects that shape a sociotechnical network. This network allows subjects - in the current virtual-physical context to interact responsibly with others to research, teach, learn, dialogue, debate, compose, evaluate, produce, disseminate and transfer within the collaborative environment of a workshop, utilizing the communicational, transformative, and open potentiality of Information and Communication Technologies (ICT). This perspective integrates the dynamic presence of technologies, interactive links, and representations in a potential space where exchanges that enable co-construction take place.

In this sense, interactive virtual spaces are considered to be habitable spaces that, when integrated with the urban landscape, are part of the human habitat. This new social space-time, augmented and hybrid, implies particular ways of dwelling that shape new identities, promoting constant alternation amongst its various worlds. The processes of design, construction, and appropriation of these spaces are not only guaranteed by the degree of accessibility to new media, but also involve the organization of complex strategies that should include the management of devices and landscapes that allow migrations and entanglements between both worlds [2].

To have access to an interactive virtual space an interface is needed, as these are mediated spaces. Interface design is not only a problem of representation, of designing the image of the information, but of the organization and the degree of accessibility to it, with the aim of reducing cognitive entropy, "...it's about designing the experience that is implied by its use" [3], about shaping interactive virtual spaces that are appropriate in the sociotechnical context of the Knowledge-Based Society, equipped with the cognitive and methodological instruments through which it unfolds, and in relation to the different profiles of its inhabitants.

“...we do not only act in the space, perceive the space, exist in the space and think about the space, but we also create space to express the structure of our world..." [4]

The space expresses our way of being-in-the-world, giving answers not only to our pragmatic necessities but also to our affective ones, to our desires, and to our fears. For the average user to be able to appropriate a virtual space and collaborate with dialogic availability, the creation of networks of trust that guarantee a 
safety threshold is indispensable, to then be able to, within the context, create an "atmosphere" that motivates participation, modelling the syntactic and semantic dimensions.

This article will contextualize in an introductory fashion the theoretical and design issues of the interfacespace, starting from a case in which an initial experimental prototype called "Memory Looms" was developed, within the framework of the interdisciplinary research project "Wheelwright, virtual-physical community: design and implementation of a Dynamic Hypermedia Device for the construction of the civitas $^{\prime 3}$, in which collaborative and plural writing of a book of community memories by the inhabitants of a town, was encouraged [5]. The aforementioned requirement paved the way for the design, development, and testing of an initial interface-space prototype for the co-production, edition, and discussion of contents, based on criteria of heuristics and usability, in relation to the complexity defined as "DHD-interactivity" [6], from an open access-open source perspective. "Memory Looms" includes an ad hoc development called "Hypermedia Memory Book", which proposes an innovative graphic and navigation interface that is technologically integrated to Moodle environment.

The project begins with an initial diagnostic carried out on collaborative systems in use, like Moodle [7] and Sakai [8], and Open Access repository systems like D-Space [9], that still exhibit weaknesses in terms of the orientation and interface comprehension requirements on the part of the users (Figure 1). The spatial proposal, the organization and visualization of resources and contents, and the strategies used to navigate the space, are unintuitive or are not clearly signposted, making them difficult to interpret, which provokes disorientation in the users that do not find what they are looking for, lose the path that they have taken, or utilize the options in an incorrect fashion.

\footnotetext{
${ }^{3}$ Santa Fe INNOVA 2009. Secretaría de Ciencia, Tecnología e Innovación. Gobierno de Santa Fe. Competition for research projects about matters of provincial interest developed by research groups belonging to the science, technology and innovation system. Project Title: "Wheelwright, comuna físicovirtual: Diseño e implementación de un Dispositivo Hipermedial Dinámico para la construcción de civitas." Institución Beneficiaria: CIFASIS. Directora: Patricia San Martín.
} 


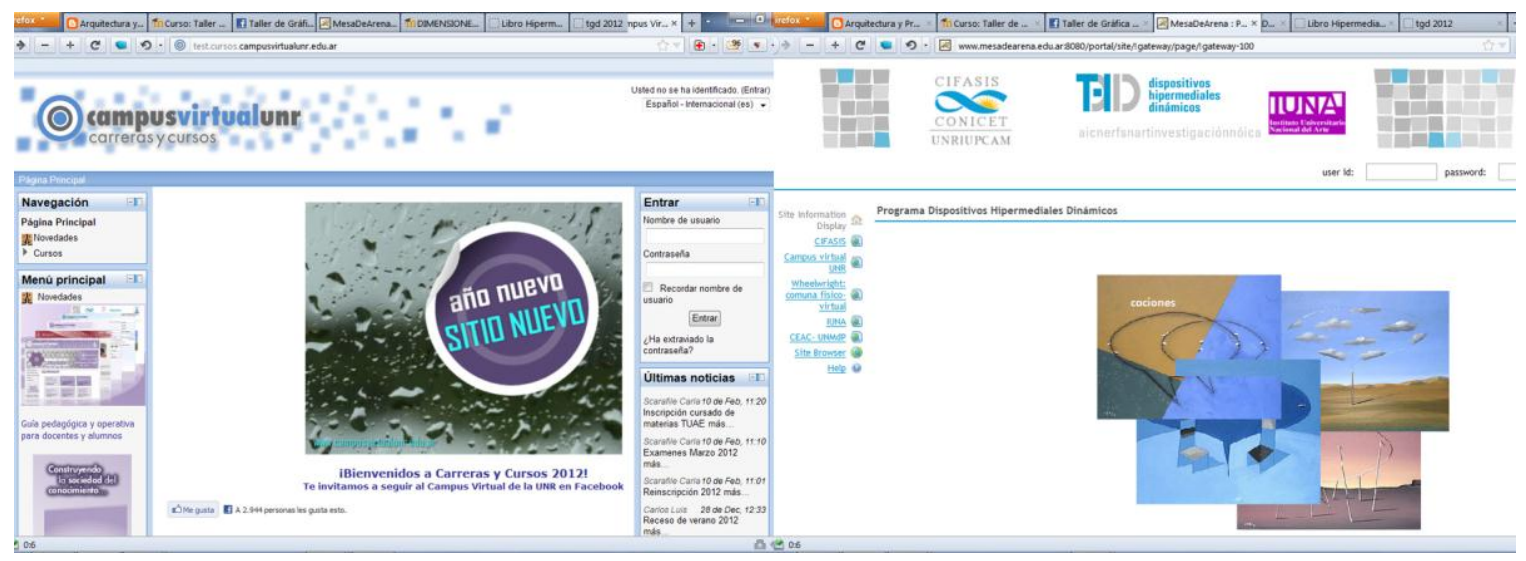

Figure 1: UNR Virtual Campus at Moodle (left) Dynamic Hypermedia Device Program at Sakai (right)

Following this introduction, a first part will cover the basics that guided the decisions and design operations implemented in the aforementioned prototype. In principle the project developed in the town of Wheelwright takes place in a holistic context that includes not only the design of the space but also, and fundamentally, the implementation of the experience that implied the deployment of a complex strategy that, according to Laddaga, corresponds to an epistemological framework in which the boundaries of traditional disciplines blur together. Then, in order to account for certain peculiar characteristics of the proposal, the concepts of syntagma and paradigm, time and space will be addressed as they relate to the database as a cultural and symbolic shape of the Knowledge-Based Society proposed by Manovich, in opposition to the narrative and cartesian lineal perspective as a "symbolic shape" of the modern era. Jay continues the debate, recovering the baroque vision as one of the scopic regimes that persists even in the present, suggesting a possible transposition to the approach proposed in the case of the design of the Hypermedia Memory Book. Afterwards, the strengths of the spatial conception of the project are described, and finally, the conclusions of the paper and possible avenues for further inquiry are presented.

\section{A POST-DISCIPLINARY CULTURE OF ART}

Art has the capacity of being a place to explore the boundaries and potential of life during a specific historical moment. For some years artists, designers, and researchers started to design and develop projects that intended to renew this capacity through the organization of complex strategies and interfaces of interdisciplinary collaboration, which make it possible to face the complexity of current reality. In general, 
these experiences may present cognitive and linguistic difficulties stemmed from the artificial separation of knowledge, and it is there that the design of the work becomes an interface in the biological sense, in a post-disciplinary ecosystem of directed action [10].

These projects require the implementation of forms of collaboration that facilitate the long term association of a group of people from different places, of different ages and from different fields; strategies that articulate processes that modify local situations and the production of representations, in a way that both aspects are mutually reinforced; and the design of publishing devices that facilitate the distribution of these collaborations in a way that maximizes their visibility for their community of origin and constitutes them as material for a debate on community identity, but is also openly available to spectators and potential readers [11].

Artists, designers and researchers are gradually more interested in participating in the development of cultural ecologies than in building works. This participation implies abandoning the gestures, forms and operations inherited from the art culture that sprung up in the last years of the 18th century and that had spread and deepened up until the last quarter century, when the institution of the work as a "personal monument" began to weaken and it became evident that the modern universe was dissipating [11].

Among the premises that sustain these kinds of projects, today works are not considered objects; they are considered to be processes that enable the participation of the spectators as co-authors of the work. Ascott, an artist renowned for his dedication to linking art, technology, and awareness since the '60s, proposes an optimistic vision of art in relation to the global systems of communication, since they place the spectator in an active position - through interaction and exploration - in the creation of an authentic artistic experience, and the collaboration in the production of meaning, evolution, and definition of the work [12].

Artists, designers, and researchers react in the face of the bankruptcy of the modern paradigm, selecting just some of its principles: the belief in the interrogative value of certain configurations of images and discourses that, articulated with the exploration of the essence and meanings of a community, set out to revise "...what a community is, has been and could be; how community connects to the individuals and what the relationships between these are like..." [11], to foster the symbolic reconstruction of collective identity. 
It is about experimental projects that, as a place for debate on the relationship between the production of representations and the new forms of citizenship, propose the integration of the virtual space with different forms of use of the urban space in which they operate, through joint actions on the part of its inhabitants. That is to say, that in this new historical context, the space of virtuality is intertwined with the urban space creating a hybrid social space-time that stores the expressions of the new forms of dwelling.

In these projects that connect art, design and technology, new types of collaborations between citizens and multidisciplinary researchers devoted to the decentralized creation of discourse and images, facilitated by devices that allow the realization and communication of the project, and that are conceived as the proper habitat of these practices, giving way to emergence of a text that integrates diverse languages and is the result of a process of plural construction [11].

Experiments with open source programming are carried out; strategies that articulate local and global networks are created; stories and anecdotes that, through different versions and discussions, update the political praxis and weave the plot of the narrative, identifying tensions and marginal phenomena and their relations with the community, fostering an act of decentralization, of research into the differences and contradictions, all of them dimensions that rehearse forms of a post-disciplinary culture of art.

\section{DATABASE AS A NEW SYMBOLIC FORM}

Following the general tendency of the new media culture towards the spatialization of all experience, Manovich considers that cultural interfaces spatialize time in unconnected sequences [13]. To prove this he resorts to the polarity between the narrative and the database, as symbolic forms that represent a different model of the world as it relates to the linguistic concepts of syntagma and paradigm. We will begin with the definition of these concepts.

The syntagma is a word or group of words that are connected amongst them constituting a functional unit. The syntagma is a combination or lineal sequence of signs (for example the nominal syntagma: the black dog). The structural articulation of a text corresponds to the syntagmatic dimension. Each element in a syntagma is chosen based on a set of elements with which it is connected: the paradigm.

The paradigm is a set of elements belonging to the same type, for example nouns. "The units that have something in common are theoretically associated and therefore constitute sets..." [13]. In a linguistic expression we choose a sign within a wide range of options. The paradigm manifests in the selection -or 
omission- of certain elements within a system of signs (words, images, etc.). The paradigms are a source of diversity.

In literary narrative, the syntagmas and the specific phrases that make up a story have a real existence, while the paradigms to which those elements belong and shape the imaginary world of the author, only exist virtually. The "database" of options -the paradigm- which is the starting point in the construction of the narrative, is implicit, while the narrative itself -the syntagma- is explicit [13].

According to Manovich, the new media turn this relationship upside down. The database (DB), a set of elements of equal hierarchy and random access that structures all the objects of the new media, has a real existence (the paradigm is explicit); while the syntagmatic chain remains latent, the narrative is virtual, potential. The user selects elements from the plane of the paradigm (spatial axis of language), and determines its sequential order -the syntagma- in the temporal transformation of the work.

The fact that all the elements of a database share the same hierarchy implies a flattening of the data that privileges space (paradigm) instead of time (syntagma), a "spatialization" that tends to denarrativize all representations and experiences. In the culture of the new media the notions of space and time vary radically when compared to previous artistic languages. Time is reduced to a presentational need, since it would be impossible to visualize all the data simultaneously, but it is not time as a narrative principle, but a fragment of time within a succession of infinite presents.

A literary narrative and a database propose a different model of what the world is. If we consider cartesian lineal perspectivism as the "symbolic form" of the modern era, we could define the DB as the new symbolic form of the knowledge-based society, a new way of structuring our experience of ourselves and the world, that presents itself as an interminable, and apparently destructured, set of images, texts, sounds, and other data. Since all of the objects of the new media respond in some way to the logical structure of the DB [13], it is pertinent to pause for a moment in the design of the DB to develop an aesthetic and an ethic for it. Creating a work in the digital environment can be interpreted as the design and construction of a means of access to a DB: an interface.

The design process of an object of the new media develops the connections between the DB -place of the contents- with the visual elements of the interface. Usually in hypermedia design, the narrative is constructed by linking the elements of the DB in a particular order, defining possible trajectories that lead 
from one element to another. For example, a virtual library constitutes a database that can be accessed from predefined metadata such as: subject, title, or author. The narrative is therefore reduced to a set of predefined links among the stored elements [13].

In the interfaces that offer a menu with multiple choices (indexed access), the user is aware that he is following one possible trajectory among others. He is selecting one trajectory from the paradigm of all the trajectories that are already defined, developing a classic syntagmatic experience that may be compared to the construction of a phrase, where successive words are chosen from many possible words using the paradigm as a starting point. The artist-designer sets the paradigm and the user sets the syntagma. Although these interfaces make the paradigmatic dimension explicit, according to Manovich they continue to be organized based on a linear sequence of screens [13], a linguistic syntagma that is typical of the old media.

\section{A PERMANENT VISUAL POTENTIALITY}

The baroque vision, defined by Martin Jay as one of the scopic regimes of the modern era, together with cartesian perspectivism and the art of describing, are revisited with the aim of establishing a transposition of the characteristics of this kind of vision, to the visualization proposed in our experimental prototype, which presents all the contents simultaneously and which will be described later.

The author considers that if it were possible to point to a scopic regime that has maintained its integrity until the present, it would be the baroque. In the 20th century we have witnessed a remarkable challenge against cartesian perspectivism and its attempt to offer a true vision, which was vigorously attacked both from the fields of philosophy and visual arts. Proof of this are the rise of hermeneutics and the return of pragmatism, structuralist and post-structuralist thought as they apply to language [14].

In this way, Jay compares renaissance art, which he considers a narrative art (human forms represented actions based on poetic texts), and dutch art, which suppresses the narrative and textual references in favor of description and the visual surface, stressing the previous existence of a world of objects, regardless of the position of the spectator. This world is not entirely contained within the frame (of the albertian window), but instead appears to extend beyond the frame. The frames are arbitrary. Dutch art, indifferent to hierarchy, focuses on the fragmented, detailed, and richly articulated surface of a world that is content with describing instead of explaining, savoring the peculiarity of the visual experience [14]. 
In opposition to the rational, lineal, solid, fixed, flat, and closed shape, monocular geometrization, together with the illusion of a three-dimensional homogeneous space of the cartesian tradition of the renaissance, the baroque was colourful, fool of nooks and crannies, unfocused, multiple and open, suggesting a permanent visual potentiality, the confused and disoriented excess of images from the visual experience, the pluralism of points of view, the illegibility and the undecipherable character of reality. The baroque rejects any attempt to reduce the multiplicity of the visual spaces to a unique, coherent essence [14].

The baroque city directed not to reason but to the senses, proposed the fragmentation of the planes, the elasticity of the curves, variety and not uniformity in its facades. The public squares had secret enclaves that gradually revealed themselves, creating a surprise effect.

The baroque vision celebrated visual madness, which can produce ecstasy in some, but perplexity and confusion in others, and acknowledged the intimate relationship that existed between rhetoric and vision (images were signs and concepts always contained an irreducible portion of the image), seeking to represent the irrepresentable. That is why it approaches the aesthetic of the sublime, due to its craving for a presence that can never be satisfied, the desire, both in its erotic and its metaphysical forms [14].

In the baroque the body returns to dethrone the detached viewpoint of the cartesian spectator. One aspect of the difference between cartesian perspectivism and other viewpoints could be in this fracture of visual space relative to the presence of the body and relates to performativity, the idea of performance and the insertion of the corporeal in the visual field [14].

\section{PROJECT DESCRIPTION}

The goal of the "Wheelwright virtual-physical township..." was to design, develop, implement, evaluate and transfer a Dynamic Hypermedia Device in a participative fashion, which enables the construction of a hypermedia memory book, retrieving the cultural heritage -tangible and intangible- of the Wheelwright community. This device is called "Memory Looms" http://dimensionesdhd.cifasis-conicet.gov.ar (Figure 2) 


\section{TELARES DE LA MEMORIA}

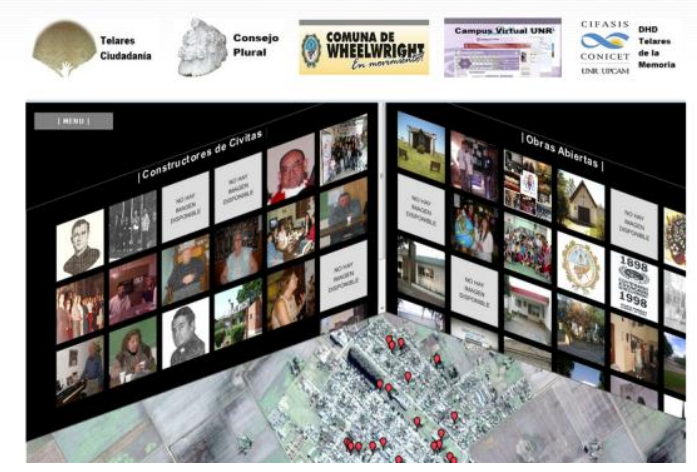

Figure 2: Memory Looms

"Memory Looms" is a dynamic and complex sociotechnical network that contributes knowledge, proposes new practices integrating ICTs and allows consensus actions that challenge the notion of citizenship in an attempt to redefine it, starting from processes that take place in the community centered on the construction and writing of memory. The intention is to make the ample processes of governance tangible, where the responsibility and concern for the common good, belong to all politically.

The diverse experiences developed in the production of the "Memory Looms" shape new forms of civic participation and artistic expression, a "cultural ecology" in which the work arise from a process of plural construction, where all participants -researchers, designers and citizens- are co-authors that collaborate in the production of meaning, from the decentralized creation of discourses, images and sounds.

The project proposes to recover values, characters, and anecdotes from the past to give meaning and identity to the present, giving way to the expression of its community in experimental form using voluntary actions and narratives in varied languages (verbal, iconic, and musical) that rearrange historic events in unpredictable ways through different versions that narrate other issues related to the life of the community, giving rise to the emergence of marginal phenomena, differences and contradictions.

As already stated, this type of projects cannot be classified from the perspective of traditional disciplines because while it does not correspond to visual arts, architecture, or anthropology, it nonetheless belongs to them all. "Memory Looms" implied the implementation of a complex strategy that unfolds in a hybrid social space-time that interweaves urban space with interactive virtual spaces, which facilitates the project 
realization and distribution. A research-action work about the characteristics and links within the community was carried out. These characteristics and links were classified in three categories of contents: builders of civitas, open works, and inhabited places, for the collaborative construction of the collective memory text that implies interests and power plays, situating the production of public goods in an arena of dispute and appropriation.

"Building a DHD entails... developing a relational, polyphonic, and hypertextual outlook focused on the possibility of generating space for social inclusion, on respect for diversity, on open access to information and knowledge, and on free citizen participation..." [15]

\subsection{The design of the complex space of the DHD}

As mentioned above, virtual space is considered part of the social space, constituting a habitable space that allows us to settle down, perform diverse activities, communicate and share meanings. Furthermore, the experiences that take place in virtual space represent spatial experiences. In this frame, it is clear that in order to be able to participate in the 2.0 society, an interface, a place where interaction is possible, will always be necessary. An interface is a space of mediation in the relation among the subjects, the digital media, and the cultural productions.

"The interface is not an object; it is a space that articulates the interaction of the human body, the tool, and the object of the action." [16]

The concepts of frontier and threshold "...conceived as a semiotic event or chronotope..." [17], are used to understand a tension that is arises in the hybrid space in relation to the appropriation, a threshold that articulates the physical with the virtual and that must be broken through: the interface, as a place that separates and unites, as a sign of resistance or of meeting, a frontier in constant movement that may exclude or provoke the dialogic meeting. This threshold, as a border area between two territories, draws a boundary between them establishing not only discontinuities, but also enabling possible "border crossings" between them. The thresholds do not refer only to the trajectories of the subjects, but also to anything that, as a sign, passes from one side to another: the representations and the discourses. 
"Memory Looms" includes several spaces of collaborative work: Citizenship Looms, Plural Management Council, Research and Development, and the "Hypermedia Memory Book", an ad hoc system that gives place to the transition of a diversity of signs in a performative space, whose interface it's based on the database as symbolic form and suggests the baroque visual culture as perceptual framework.

The Hypermedia Memory Book proposes an experience that fragments space-time in a superimposition of infinite presents. In a traditional hypermedia interface the narrative is built through pre-established links between the database and the interface, where the access and visualization of each content is consecutive, organizing itself starting from a linear sequence of screens, a linguistic syntagma that is typical of old media where time is the narrative principle.

There are no previously defined trajectories in the Hypermedia Memory Book, as the narrative is constructed by each subject's contingent, particular outlook, establishing his own links with the scene in each navigation and visualising the relations that he himself has created between the elements of the database. The paradigm is explicit: the complete DB is always present before the user with all the available categories, objects, and options. Yet this interface proposes an innovative syntagma: all the contents can be accessed simultaneously (Figure 3) and not starting from a linear sequence of screens, a spatial syntagma which leads to visualize everything at the same time from multiple viewpoints. Navigation constitutes a complex experience full of heterogeneities, lacking linearity, which permits the oscillation between the observation of the whole and the plotting of trajectories that narrate unique events.

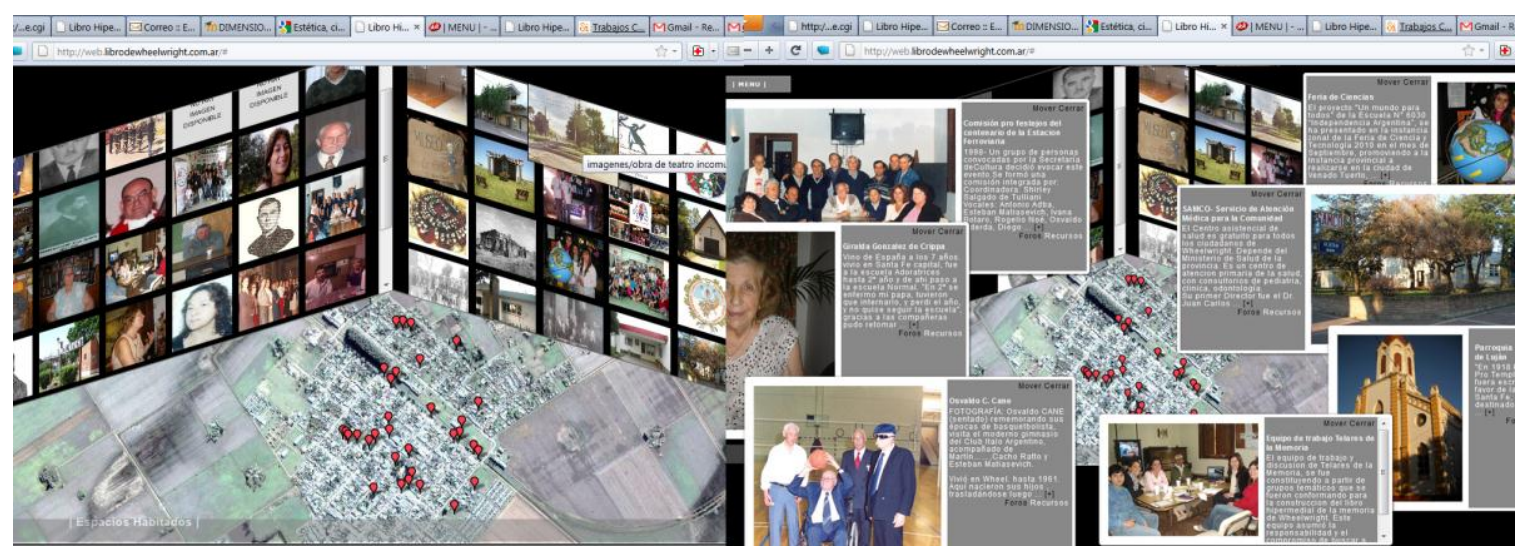

Figure 3: Hypermedia Memory Book: Paradigm (left) Syntagma (right). 
The category of chronotope developed by Bakhtin proposes that the social construction of time is inseparable from the configuration of space, from the social relations and from the cultural imaginary of a society. Time and space constitute the categories that organise what is real and every symbolic construction of subjects and collective identities [18]. The notion of space takes on vital importance both as product and producer of interactions and interrelations, condition of possibility for multiplicity and diversity, changing, in process, unfinished; hence its symbolic, political, and identitarian potentiality [19].

Since a spatial proposal denotes a way of understanding the world, it involves the desire to provoke specific sensations, and offers the possibility of updating certain rites and generating certain spatial appropriation behaviors. From the symbolic point of view, the design of the graphic interface of the Hypermedia Book offers the representation of a three-dimensional space (from three juxtaposed planes that present the contents). The intention is to spatialize the experience so that the users perceive themselves "inside" a suggestive space that stimulate participation, the place of the inscriptions, stories, journeys and the innumerable possibilities of reading the same writing [20].

“...all information, all data, can become architectonic and habitable... placing humans within the space of information..." [21]

The interface acts as a hub and threshold that provides access to an underlying database but it can also transform data retrieval into a performance, into a unique experience for the user. Since virtual space is considered a habitable space, from the functional point of view, the interface-space of the Hypermedia Book offers simultaneous navigation throughout the database in an "open plan" that guarantees orientation. In this unique polyfunctional and proliferating non-hierarchical space is where all events and interactions occur in parallel. Its complexity is expressed through the surface fragmentation, the superimposition and the articulated diversity that, as in dutch art, enhance the particularity of visual experience.

The interface-space of the Hypermedia Book http://dimensionesdhd.cifasis-conicet.gov.ar/libro/ is virtual, in the sense of latent potential [22] which is gradually discovered as the baroque city, “... and it is updated in a circumstantial and creative way because it depends on an event" [23]. It is also fluid, continuous, topological, and tries to blur the boundaries between inner and outer, describing a multi-coloured and full of nooks world of objects that seems to overflow the screen frame. 
The interface-space of the Hypermedia Book is infinite, in its unsatisfied desire of representing the boundless character of reality, which manifests itself in a fractal conception of space that houses no end of objects, participants and relations in a dynamic way, as it grows and changes its shape and content constantly because of the contributions and interactions. As baroque vision, it offers a profusion of images that suggests a permanent visual potentiality from a multiplicity of points of view, which is related to performativity and the entry of the body in the visual field.

The Hypermedia Book is open, it relates to and is inter-defined with other sub-spaces of "Memory Looms" in Moodle environment ("Citizenship Looms", "Plural Management Council"), where the debates and exchanges that reinforce feelings of belonging in the citizenry take place.

The Hypermedia Book is constructed plurally, all the citizens may contribute their experiences, memories and dreams; and promotes the construction of civitas, the participation and the commitment of citizens with the social, cultural, and political life of their own community, knotting together individual stories with those that gave way to public actions, to foster a reflective view of themselves and reinforce the collective identity.

\section{INHABITING A NEW SPACE-TIME}

The design and management of the different spaces created around the writing of plural memory entailed moments of conflict and resistance that evidenced -though complex processes of discussion- old confrontations, power relations and conflicting interests within the community comprised by citizens and researchers. These facilitate the comprehension of the dynamics of participation in the construction of civitas, mediated by the new media [2].

The hypermedia writing of memory gradually acquired unique characteristics as the community appropriated the project as its own and groups that were socially relevant, heterogeneous, and with diverse interests started to form; groups of citizens and researchers that gradually "constituted" the artifacts [24] from the meanings that they attributed to them while dwelling in this hybrid space that oscillates, opposing or joining the physical and the virtual.

The project gathered a large number of people who collaborated in the writing of the book and fostered the exploration of the issue in other settings. For example, during the political campaign leading up to 2011 elections, it generated a kind of circulation that resembles that of an assembly that generated the debate on 
the political dynamics of the community, a debate on the present organised in the light of the reflection of a past community that was updated through discursive development in the hypermedia book. In parallel, the project was followed by a growing number of inhabitants that witnessed the proliferation of contributions in its website, where the inputs were more and more numerous, “... as if certain unvoiced wishes had found an appropriate language...” [11].

\section{CONCLUSIONS AND FUTURE WORK.}

The different moments of the project generated an accumulation of unforgettable experiences that turned into a multiplicity of words and images that expanded through informal media or planned strategies: meetings, symposiums, and workshops in different parts of town; interviews with local protagonists on the town radio and in a high-impact regional newspaper; distribution of posters; and a bus excursion to a nearby rural area in which students, inhabitants, researchers, and local officials participated. These activities allow reflecting upon the behaviors, meanings, and diverse "thresholds" that were constructed by the actors themselves during this process, and suggest new ways of being-in-the-world.

This experience gave way to a constant development of the "Memory Looms" prototypes during 2010 and 2011, with the goal of completing the first experimental prototype which will be transferred to the community of Wheelwright by approximately March 2012. This involves the installing the system in the township's server and the autonomous management of the DHD, both in its social and technological aspects. The final adjustments carried out correspond to the optimization of the information loading chips, help for these loads, and the integration of the interface of the Hypermedia Book to Moodle environment, associating it to the tool glossary.

The reflection carried out in this article has contextualized the interface-space of the DHD in an introductory fashion as it relates to the "Memory Looms" project. However, it is considered that the spatial and technological proposal exceeds the scope of this project and that it will be modelled and then transferred to open source management systems such as Moodle, Sakai, or D-Space, as a new form of navigation and content visualization in different dimensions.

The issue and the meta-space of the DHD will be further explored and developed, integrating in its multiple dimensions: spaces of collaborative construction of knowledge, the Moodle platform, the Facebook and Skype systems, the Prezi presentation editor, etc., according to the strengths of each one and with the goal 
of making resource use more intuitive and unforced, through an interface-space that allows access and simultaneous availability to all of them.

\section{References}

1. San Martín, P., Hacia un dispositivo hipermedial dinámico. Educación e investigación para el campo audiovisual interactivo, Colección Música y Ciencia, $\mathrm{N}^{\circ}$ III, Universidad Nacional de Quilmes Editorial, Buenos Aires, 2008.

2. Tosello, M., Martino, S., Rodriguez, G., El libro hipermedial de la memoria plural. Una historia sin fin, in: Chiarella, M., Tosello, M., eds., Cultura Aumentada: XV SIGraDi Conference Proceedings, Universidad Nacional del Litoral, Santa Fe, 2011, 551-554.

3. Montagú, A., Groisman, M., Pimentel, D., Cultura Digital. Comunicación y Sociedad, Paidos, Buenos Aires, 2004.

4. Norberg Schulz, C., Existencia, espacio y arquitectura, Blume, Barcelona, 1975.

5. San Martín, P., Martino, S., Tosello, M., Guarnieri, G., Rodriguez, G., Un Dispositivo Hipermedial Dinámico para la construcción participativa del patrimonio intangible, in: Terceras Jornadas del Mercosur sobre el Patrimonio Intangible Conference, Universidad Nacional de Mar del Plata-CICOP, Mar del Plata, 2011.

6. Guarnieri, G., El modo interactivo del Dispositivo Hipermedial Dinámico, PhD Thesis, Universidad Nacional de Rosario, Rosario, 2011.

7. www.moodle.org [10-01-2011].

8. www.sakaiproject.org [10-01-2011].

9. www.dspace.org [10-01-2011]. 
10. Martin Iglesias, R., Hacia un nuevo paradigma de diseño colaborativo, in: Chiarella, M., Tosello, M., eds., Cultura Aumentada: XV SIGraDi Conference Proceedings, Universidad Nacional del Litoral, Santa Fe, 2011, 123-126.

11. Laddaga, R., Estética de la emergencia, Adriana Hidalgo Editora, Buenos Aires, 2010.

12. Ascott, R., El web Chamántico. Arte y conciencia emergente, http://alepharts.org/pens/ascott.html [10-01-2012].

13. Manovich, L., El lenguaje de los nuevos medios de comunicación, Paidós Comunicación, Buenos Aires, 2006.

14. Jay, M., Regímenes escópicos de la modernidad, in: Foster, H., ed., Campos de fuerza. Entre la historia intelectual y la crítica cultural, Paidós, Barcelona, 2003, 221-252.

15. San Martín, P., Guarnieri, G., Construir un dispositivo hipermedial dinámico en la universidad pública, Revista Cuadernos Sociales, 2009, Vol. 9, Universidad Nacional de Rosario, 111-127.

16. Bonsiepe, G., Del objeto a la interfase. Mutaciones del diseño, Infinito, Buenos Aires, 1999.

17. Gustafsson, J., Apacible fluye la frontera. Diálogo, exclusión y utopía en Machuca y Los tres entierros de Melquíades Estrada, deSignis, 2010, N¹5, La Crujía, Buenos Aires, 82-90.

18. Dalmasso, M., Andacht, F., Fatala, N., deSignis, 2010, N¹5, La Crujía, Buenos Aires, 7.

19. Arfuch, L., Espacio, tiempo y afecto en la configuración narrativa de la identidad, deSignis, 2010, Nº15, La Crujía, Buenos Aires, 32.

20. Machado, A., El advenimiento de los Medios Interactivos, in: La Ferla, J. y Groisman, M., eds., El Medio es el Diseño, Oficina Publicaciones Ciclo Básico - UBA, Buenos Aires, 1996.

21. Novak, M., Liquid Architectures in Cyberspace, in: Benedikt, M., ed., Cyberspace: First Steps, The MIT Press, Cambridge, 1991, 226-249. 
22. Levy, P., Becoming Virtual: Reality in the Digital Age, Da Capo Press, 1998.

23. Giordano, R., Tosello, M., Laberinto, una Biblioteca para la Virtualidad, in: Bermudez, J., Cardozo, J., Montagu, A., Paysse, M., Stipech, A., eds., III SIGraDi Conference Proceedings, Universidad de la República, Montevideo, 1999, 83-86.

24. Thomas, H., Buch, A., Actos, Actores y Artefactos, Universidad Nacional de Quilmes, Buenos Aires, 2008. 